\title{
The impact of higher voltage and current harmonics on the operation of electrical systems
}

\author{
A $N$ Egorov $^{1}$, Ya $S$ Kharitonov ${ }^{1}, V M$ Khubieva $^{2}, I A$ Yakushev $^{2,}{ }^{*}, N V$ Golubtsov $^{3}$ and $Z M$ Shakurova $^{4}$ \\ ${ }^{1}$ PJSC ALROSA, Mirny 678170, Sakha (Yakutia), Russia \\ ${ }^{2}$ North-Eastern Federal University n.a. M.K. Ammosov, Polytechnic Institute (branch) in Mirny, Mirny 678170, Sakha (Yakutia), Russia \\ ${ }^{3}$ Nizhny Novgorod State Technical University n.a. R.E. Alekseev, Nizhny Novgorod 603950, Russia \\ ${ }^{4}$ Kazan State Power Engineering University, Kazan 420066, Russia
}

\begin{abstract}
The article deals with the assessment of impact of higher harmonics on the operation of variablefrequency electric drive systems used in processing units at mining enterprises. Beyond that, energy efficiency and operation experience of variable-frequency electric drive usage at mining enterprises were studied. The advantages and drawbacks of implementation of variable-frequency electric drive systems were found. They include energy saving and reducing maintenance costs for processing units on one hand, as well as losses due to their incorrect selection and electromagnetic compatibility distortion on the other hand.
\end{abstract}

\section{Introduction}

The rapid development of industrial electronics, measurement equipment and information technology provides improvement of the automation hardware for the technological processes at mining enterprises. The development of process control systems is aimed at the improvement of operational modes of the processing units and processes in order to achieve the required productivity and quality alongside with the maximum possible reduction of operational costs, including the maximum reduction of energy input.

The reduction of the energy input for technological processes is achieved through the adjustment of conversion processes for the energy needed to perform the final work output $[1,2]$. Currently, heavy processing units at mining enterprises use variable-frequency electric drives to improve their energy efficiency and ensure the optimal operation $[3,4]$.

The implementation of variable-frequency electric drives to improve the energy efficiency of the technological processes at mining enterprises can result in a multiplied economic effect, provided that introduction and further operation of the electric drive systems are performed in a correct way [5]. Apart from the energy saving, the efficient management of the energy conversion and transmission processes through variable-frequency drive allows achieving the following results: improving actuators' performance through brand new solution for technological problems via process automation; reducing maintenance and repair costs for the processing equipment due to the more seamless transition processes and elimination of the surplus energy diffusion in the drive unit's parts and elements; increasing the operating life of electric motors and actuators [6].

This causes a wide usage of variable-frequency drives at mining enterprises, especially at concentrators and mines. The mechanisms using variable-frequency drives can be divided into two groups. The first group comprises the units in which the automated speed control follows some technological parameter (fluid pressure in pipeline, level of liquid in sump, air pressure sink in vent duct, etc) to provide energy savings; such units include pumps and fans $[7,8]$. The second group comprises the mechanisms, in which the speed control is necessary to maintain the required operational modes for the processing unit [9]. This group includes, for example, mine hoists and auxiliary winches of floating mines.

The electric drive coordinate control is performed with the help of frequency converters, which are nonlinear devices, because the conversion of power parameters in them is achieved through the switching of semiconductor valves. The proportion of nonlinear loads in the electrical grids of mining enterprises is growing steadily due to the continuous increase in nominal power of frequency converters. For example, the power rating of hoisting machines with variable-frequency drives today amounts up to $5 \mathrm{MW}$, while the total installed capacity of the mine is about $30 \mathrm{MW}$. At this, large single nonlinear loads distort voltage and current waveforms of the enterprise power line to a greater extent.

Frequency converter manufacturers research and develop schematic solutions to reduce the levels of higher harmonic components. Nevertheless, the experience shows that power grids with valve inverters have higher harmonics of voltage and current. The level

* Corresponding author: ia.yakushev@s-vfu.ru 
of these harmonics and their configuration depend on the type of the converter, the power circuit layout, the schematic solutions, the parameters of the valve control system, etc.

\section{Research goal and objectives}

The goal of this research is the assessment of the higher harmonics impact on the operation of variable-frequency electric drive systems at mining enterprises. In order to achieve this goal, it is necessary to complete the following objectives: to analyze the experience of the variable-frequency electric drive system usage in mining enterprises; to investigate and analyze the practices of using the variable-frequency electric drives in various processing units; to study the electromagnetic compatibility of the supply line using high voltage and low voltage frequency converters.

\section{Research methods}

In order to investigate and analyze the experience of implementation of variable-frequency electric drive systems in various processing units at mining enterprises, we utilize the accumulated theoretical and experimental data, confirmed with the results of mathematic simulation of operational modes for the variable-frequency drive systems in MatLab software package $[10,11]$

To assess the impact of higher harmonics on the operation of variable-frequency drive systems, we use the instrumental measurement methods for the power quality indices, subjected to the Russian State Standard GOST 32144-2013 (EN 50160:2010, NEQ). According to the GOST, the measurements shall be taken using a certified power quality analyzer within 7 days at 10 minute interval in at least two points of the power supply system.

\section{Research results}

The detailed analysis of the high voltage frequency converter efficiency in electric drive system of the main fan unit of the underground mine is available at [12]. The authors measured the operational efficiency of one of the most advanced modern high voltage frequency converters: Power Flex 7000. The results of the efficiency analysis of the main mine fan's work via mathematic simulation and instrumental measurement methods show the real improvements in energy saving after the complete replacement of the frequency converter - motor - fan unit package: the savings amounted to over $50 \%$, which can bring over $\$ 200000$ economy in a year.

The analysis of efficiency of introduction of high voltage frequency converter into electric drive system of the slurry pump of the concentrator is available at [13]. This paper shows operational feature of the currently best (in authors' opinion) high voltage frequency converter, ACS5000. After installing the variable- frequency electric drive to the slurry pump, a significant reduction of energy consumption was achieved, and it also led to the reduction of pump and pipe line maintenance and repair costs through ensuring seamless transition processes and hydraulic shocks.

There is an example of installation of a high voltage variable-frequency drive on the recirculated water supply pumping unit of a $315 \mathrm{~kW}$ concentrator. Before the upgrade, the pumping unit was actuated by uncontrolled electric drive system based on high voltage asynchronous motor with direct on line start. With a view to saving the capital investments for the upgrade and considering the insufficient power of the department networks for $0.4 \mathrm{kV}$, the enterprise managers decided to install high voltage frequency converters. However, in [14] the authors proved that low voltage frequency converters would be more economical, even taking into consideration the extra costs for purchasing low voltage electric motors and two standard transformer stations. This is due to the significant reduction of expenses for the frequency converter maintenance and repair, spare parts, tools and accessories. For example, the price for just one dysfunctional IGCT thyristor for a high voltage frequency converter is about $\$ 12.000$, which can compare with the price for an entire low voltage converter $[15,16]$.

Meanwhile there is also some negative experience of introducing and operating variable-frequency electric drives at mining enterprises. For example in 2017, low voltage frequency converters were installed on the majority of actuators of a diamond floating mine. Almost all mechanisms with newly installed converters performed their job well, except the bow auxiliary winches. While analyzing this case, the authors found two key reasons: the first one is that at the stage of purchasing new converters the vendor received only partial information about the mechanisms to be controlled by the electric drive system; the second one is that the vendor did not have the experience of installing frequency converters onto dredge actuators, and the vendor did not carry out the detailed object audit. It turned out that the frequency converters supplied for the auxiliary winch drives only had the $\mathrm{u} / \mathrm{f}$ control. The vector control capacity will insignificantly increase the price of frequency converter, but it will also allow maintaining the motor's momentum at the required level at any speed, which is vital for such mechanisms.

Therefore, despite the positive economic effect of installing variable-frequency electric drives, there is also some negative impact, if the frequency converters were selected or installed in a wrong way.

Further we move to the main problem of our research.

Higher harmonics increase the energy losses on the elements of the power network and reduce their operating life [17]. There are practical records of the capacitor breakage in the input power supply filter of frequency converters in a skip hoisting plants used in an underground mine. The hoisting plants use recuperation electric drives to recover the energy when taking down the hoisting container. A simplified basic circuit diagram for such a converter is shown in Figure 1. The power 


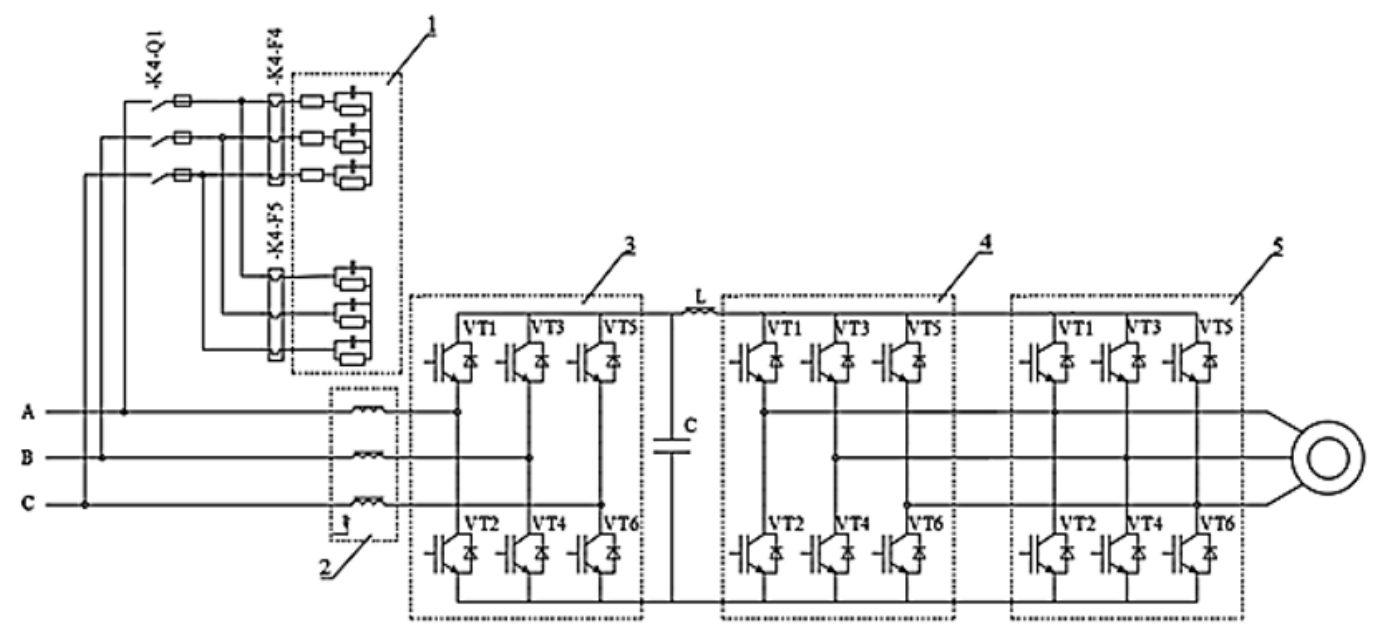

Fig. 1. Simplified basic circuit diagram of the power circuit of the frequency converter.

circuit of the converter comprises the rectifier 3 and two parallel (to increase the power output) autonomous voltage inverters 4 and 5 . The input circuit of the converter also connects the choke 2 and the power supply filter 1 .

In order to find the causes for power supply filter capacitor and the frequency converter failures, the operational modes of the mine hoisting plant and the power supply network were examined. During these investigations and consultations with the manufacturer of the frequency converter, higher harmonic components in the power supply network were suggested as the main reason for capacitor failure, because they shorten the capacitor's operating life.

In order to disprove or confirm this hypothesis, the indices of power quality were instrumentally measured [18-20].

Higher harmonics in mine power supply networks can be generated by the frequency converters of hoisting machines and main fans. Moreover, nonlinear loads in the mine are distributed. For example, when main fan 1 is in operation, all the hoisting machines in the surface unit are switched to the second power terminal, because main fan 1 is powered from the first terminal. When fan 1 is off and fan 2 is on, the hoisting machines become powered through the first terminal.

The hoisting machine of the blind skip shaft is located in the underground unit of the mine, and it is powered through the first terminal. The mine's main fan is replaced one a month, which means that the structure and the level of the higher harmonics on the frequency converter of the blind skip shaft also changes every month. Therefore measurements of the power quality indices were taken with different sets of nonlinear loads on the first terminal.

Instrumental measurement was carried out in accordance with the requirements of GOST simultaneously at three points in the power supply system. The first point of measurement was in cell 9 of the first terminal of central distribution station 1 . The second point of measurement was in cell 2 of the first terminal of distribution substation 3 . The third point of measurement was directly on the frequency converter input terminal. Power quality in all three control points fails to meet the requirements for nonlinear harmonic distortion factors of the 17th and 19th.

Figures 2 and 3 show graphs of daily nonlinear harmonic distortion factor variance for 17 and 19 degrees, respectively. Frequency converter manufacturer's specialists believe that these harmonics cause the failures of power supply network filter capacitors.

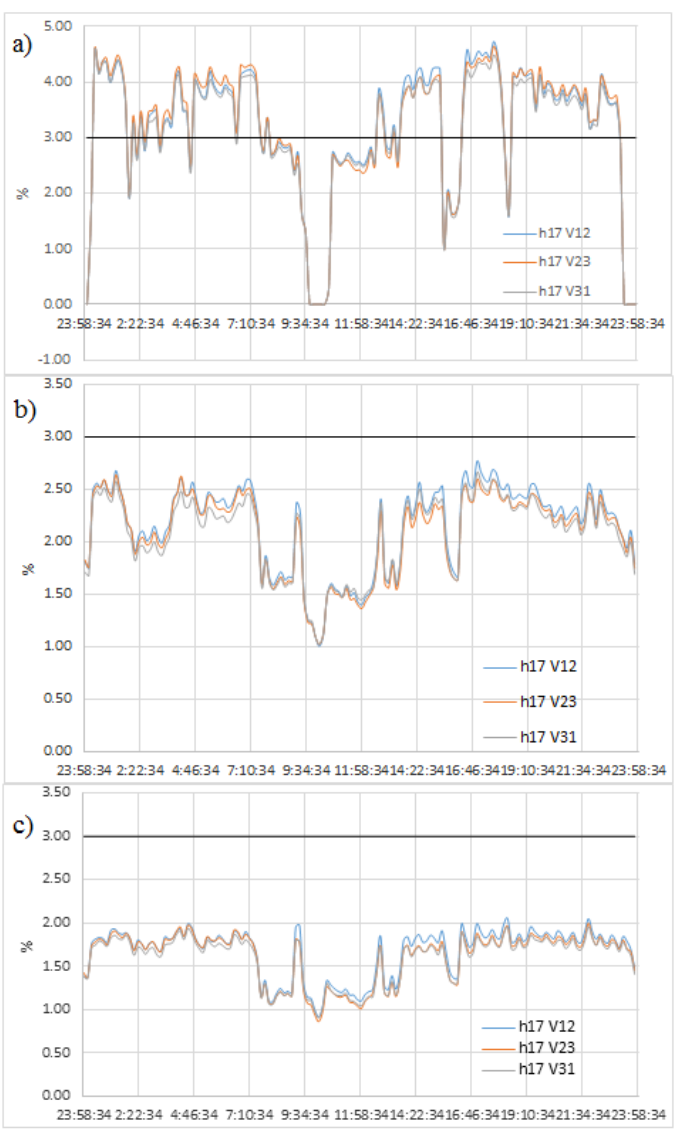

Fig. 2. Graphs for the nonlinear harmonic distortion factors of degree 17: a) third point, b) second point, c) first point. 


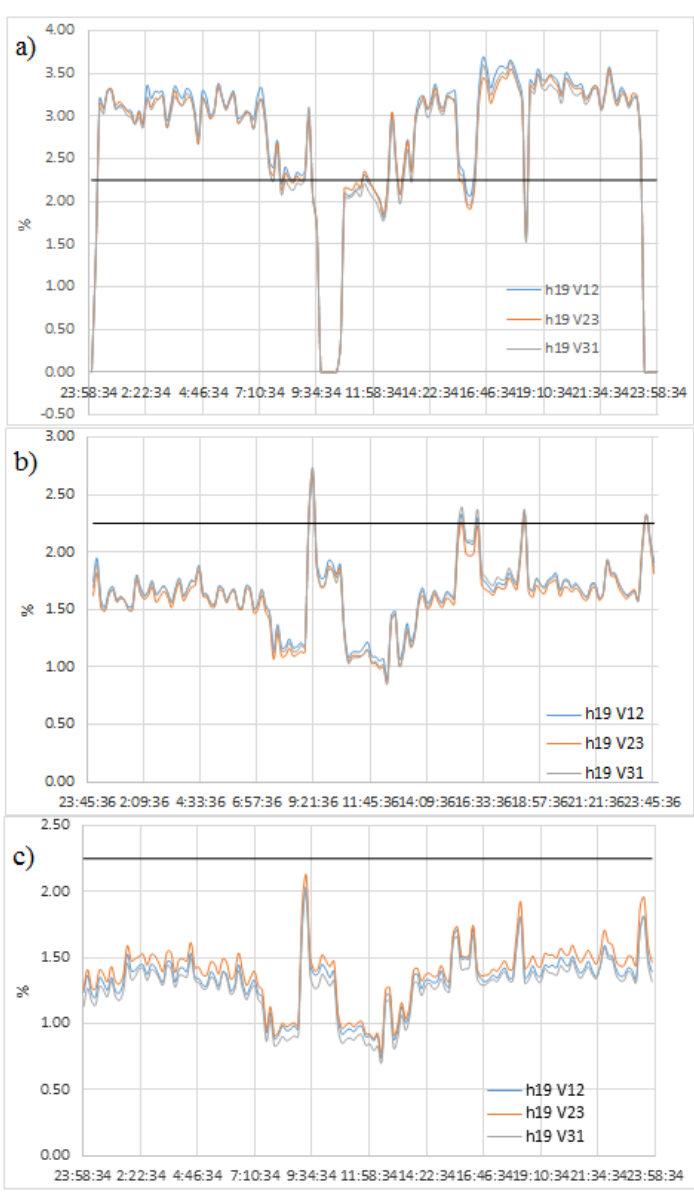

Fig. 3. Graphs for the nonlinear harmonic distortion factors of degree 17: a) third point, b) second point, c) first point.

The results of processing and analysis of the measured data from skip hoisting machine working without the main fan, but with the other mine's hoisting machines in all three points show the power quality indices satisfying the requirements of GOST [21, 22].

It is worth noting that when the skip hoisting machine operates without the main fan, the failures of the frequency converter become considerably fewer. Previous observations over frequency converter failures show that error log has records of voltage overload alarms in the DC link. The converter measurement system works fine and records real voltage overload in the DC link when the hoisting machine is operated in dynamic modes. Taking into consideration that reducing harmonic components in power supply network lead to the reduction of failures, it can be assumed that the main cause of converter failure is the change of properties of the supply network filter capacitors exposed to higher harmonics.

It is clear that the higher harmonic components in mine power supply networks influence the work of frequency converter of the skip hoisting machine. They lead to the gradual deterioration of the capacitors of the frequency converter supply network filters and, in the end, to the capacitor failure [23]. The gradual change of capacitor parameters influences the failure rates of the converter [24].

The authors believe that the further large-scale and thorough research on the efficiency of variable- frequency drive usage shall take the following directions: engineering requirements for mining machinery [25]; operational features of frequency converters at mining enterprises [26]; fundamental principles of the development of power circuits for frequency converters; fundamental principles for the variable frequency electric drive control; technical and economic analysis of the modern frequency converter market [27]; researching modern methods for collecting, processing and analyzing information about the variablefrequency drive systems operation; diagnostic methods for the semiconductor power converter equipment.

\section{Conclusions}

The practical experience of operating variable-frequency electric drive at mining enterprises' units and equipment was analyzed. Its positive and negative effects were discussed. The impact of higher harmonics on the operation of variable-frequency electric drive systems was assessed. It was proved that higher harmonics adversely affect the operation of frequency converters and they can lead to the failure of some elements of a variable-frequency electric drive system. The results of the analysis allowed to define the problems connected with usage of the variable-frequency electric drive and with further improvement of its design. Solving these problems will help to improve the efficiency of this type of electric drive.

\section{Acknowledgments}

This work was financially supported by Kazan State Power Engineering University.

\section{References}

1. S.A. Panihidnikov, S.V. Novoselov, A.V. Kulinkovich, Ugol', 11, 64 (2018)

2. V.I. Golik, V.I. Komashchenko, V.S Morkun, N.V. Morkun, S.M. Hryshchenko, Science and Innovation, 14, 29 (2018)

3. B.I. Abramov, L.K. Datskovskii, I.K. Kuz'min, Y.V. Shevyrev, Russian Electrical Engineering, 88, 159 (2017)

4. K.A. Zmieva, Russian Electrical Engineering, 86, 239 (2015)

5. O.V. Fedorov, Applications and Manufacturing, Int Conf on Industrial Engineering, 8076221 (2017)

6. A.M. Kostygov, A.V. Kychkin, S.A. Artemov, Russian Electrical Engineering, 86, 667 (2015)

7. E.S. Shangin, R.V. Solovyov, Oborudovaniye $i$ tekhnologii dlya neftegazovogo kompleksa, 16 (2018)

8. N.P. Ovchinnikov, Power Technology and Engineering, 52, 552 (2019)

9. M.A. Averbukh, D.A. Prasol, S.V. Khvorostenko, Proceedings of Irkutsk State Technical University, 21, 75 (2017) 
10. A.S. Semenov, V.M. Khubieva, Ya.S. Kharitonov, Int. Russian Automation Conf, 8501666 (2018)

11. A.S. Semenov, I.A. Yakushev, A.N. Egorov, Modern high technologies, 8, 56 (2017)

12. A.N. Egorov, A.S. Semenov, Yu.V. Bebikhov, A.A. Sigaenko, Int Journal of Energy for a Clean Environment, 20, 153 (2019)

13. A.N. Egorov, A.S. Semenov, O.V. Fedorov, Int. Multi-Conf. on Industrial Engineering and Modern Technologies, 8602676 (2018)

14. A.N. Egorov, A.S. Semenov, O.V. Fedorov, Yu.S. Kharitonov, Gornyi Zhurnal, 2, 77 (2019)

15. Y. Iwahashi, Y. Mizuno, M. Hara, R. Tagami, M. Ishigaki, Microelectronics Reliability, 52, 2430 (2012)

16. S.R. Jang, H.J. Ryoo, G. Goussev, G.H. Rim, IEEE Transactions on Plasma Science, 40, 2561 (2012)

17. A.V. Shestakov, V.V. Zhelnin, R.N. Ismiev, Russian Electrical Engineering, 87, 333 (2016)

18. N.M. Kuznetsov, A.S. Semenov, Yu.V. Bebikhov, A.V. Rybnikov, Gornyi Zhurnal, 1, 23 (2014)

19. N.M. Kuznetsov, A.S. Semenov, Measurement Techniques, 57, 417 (2014)

20. D. Feng, M. Lu, J. Lan, L. Sun, IET Generation, Transmission \& Distribution, 10, 3322 (2016)

21. A.S. Semenov, V.A. Bondarev, Fundamental research, 4(1), 112 (2016)

22. A.S. Semenov, V.A. Bondarev, S.A. Zagolilo, Fundamental research, 9(1), 86 (2016)

23. A.A. Shpiganovich, O.V. Fedorov, K.A. Pushnitsa, E.V. Churkina, Izvestiya Vysshikh Uchebnykh Zavedenij. Chernaya Metallurgiya, 60, 726 (2017)

24. A.N. Shpiganovich, V.I. Zatsepina, A.A. Shpiganovich, V.M. Stepanov, EAI Endorsed Transactions on Energy Web, 5, 10 (2018)

25. V.N. Fashchilenko, S.N. Reshetnyak, Gornyi Zhurnal, 7, 80 (2017)

26. K.N. Kopylov, S.S. Kubrin, S.N. Reshetnyak, Ugol', 10, 66 (2017)

27. Y.V. Shevyrev, O.V. Fedorov, A.S. Sarvarov, Mining Informational and Analytical Bulletin, 3, 82 (2018) 